Naohiko Seki • Atsushi Hattori · Sumio Sugano

Yutaka Suzuki • Akira Nakagawara

Miki Ohhira • Masa-aki Muramatsu • Tada-aki Hori

Toshiyuki Saito

\title{
Isolation, tissue expression, and chromosomal assignment of a novel human gene which encodes a protein with RING finger motif
}

Received: June 22, 1998 / Accepted: July 31, 1998

\begin{abstract}
We identified a novel gene encoding a RING finger (C3HC4-type zinc finger) protein from a human neuroblastoma full-length enriched cDNA library. This cDNA clone consists of 1919 nucleotides with an open reading frame of a 485-amino acid protein. From reverse transcription (RT)-polymerase chain reaction (PCR) analysis, the messenger RNA was ubiquitously expressed in various human adult tissues. The chromosomal location of the gene was determined on the chromosome $6 \mathrm{p} 21.3$ region by PCRbased analyses with both a human/rodent monochromosomal hybrid cell panel and a radiation hybrid mapping panel.
\end{abstract}

Key words RING finger · Full-Length enriched cDNA library $\cdot$ Chromosome 6 p21.3 $\cdot$ RH mapping

\section{Introduction}

Zinc finger motifs consist of several subfamilies based on their different types of fingers, categorized by the nature

N. Seki · A. Hattori · T. Hori · T. Saito $(\bowtie)$

Genome Research Group, National Institute of Radiological

Sciences, 4-9-1 Anagawa, Inage-ku, Chiba 263-8555, Japan

Tel. 81-43-206-3135; Fax 81-43-251-9818

e-mail: t_saito@nirs.go.jp

S. Sugano · Y. Suzuki

Department of Virology, Institute of Medical Science, the University of Tokyo, Shirokanedai, Minato-ku, Tokyo 108-8639, Japan

A. Nakagawara $\cdot$ M. Ohira

Division of Biochemistry, Chiba Cancer Center, 666-2, Nitona,

Chuoh-ku, Chiba 260-8717, Japan

M. Muramatsu

Helix Research Institute, 1532-3 Yana, Kisarazu, Chiba 292-0812,

Japan and Department of Bioregulation, Medical Research Institute,

Tokyo Medical Dental University, Bunkyo-ku, Tokyo 113-8510,

Japan

A. Hattori

Biotechnology and Medical Engineering Field, Aisin Cosmos R\&D

Co., Ltd., 5-2-11 Sotokanda, Chiyoda-ku, Tokyo 101-0021, Japan and spacing of their zinc-chelating residues (Schwabe and Klug 1994; Mackay and Crossley 1998). It is estimated that there are 500 zinc-finger proteins encoded in the yeast genome and that approximately $1 \%$ of all mammalian genes encode zinc fingers (Mackay and Crossley 1998). The RING finger is a C3HC4-type zinc finger motif, and members of the RING finger family are mostly nuclear proteins; this motif is involved in both protein-DNA and proteinprotein interactions (Freemont et al. 1991, Saurin et al. 1996).

\section{Isolation of cDNA clone for novel RING finger protein}

A cDNA clone for a novel RING finger protein was isolated from a full-length enriched cDNA library constructed from a neuroblastoma (NB) sample, using the oligo-capping method, as described previously (Maruyama and Sugano 1994; Suzuki et al. 1997). Here we report the sequence features, tissue expression, and chromosomal assignment of the gene.

From the one-pass sequencing and database search, this cDNA clone did not match any human gene. The entire sequence of this clone was determined by a shotgun strategy (Ohara et al. 1997). The isolated cDNA clone was 1919bp in length and had an open reading frame of 485 amino acids (Fig. 1). The predicted protein of 485 amino acids had a calculated molecular weight of approximately $56 \mathrm{kDa}$. Our sequence analysis of the cDNA clone revealed a highly conserved motif consistent with a RING finger (C3HC4type zinc finger) domain encompassing amino acid residues

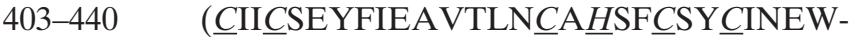
MKRKIEC $\underline{C I} \underline{C})$.

\section{Tissue expression of the novel human gene}

We examined the tissue distribution of the transcript in various human adult tissues by reverse transcription- 
ATGGGGGAGCCCGGCTTCTTCGTCACAGGAGACCGCGCCGGTGGCCGGAGCTGGTGCCTG $M \quad G \quad E \quad P \quad G \quad F \quad F \quad V \quad T \quad G \quad D \quad R \quad A \quad G \quad G \quad R \quad S \quad W \quad C \quad L$ CGGCGGGTGGGGATGAGCGCCGGGTGGCTGCTGCTGGAAGATGGGTGCGAGGTGACTGTA

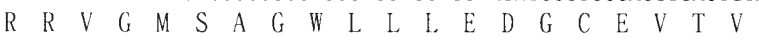
GGACGAGGATTTGGTGTCACATACCAACTGGTATCAAAMTCTGCCCCCTGATGATTTCI

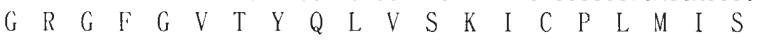
CGAAACCACTG'TGTTTTGAAGCAGAATCCTGAGGGCCAATGGACAATTATGGACAACAAG

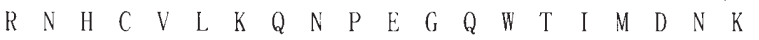
AGTCTAAATGGTGTTTGGCTGAACAGAGCGCGTCTGGAACCTTTAAGGGTCTAITCCATT $\begin{array}{llllllllllllllllllll}S & L & N & G & V & W & L & N & R & A & R & L & E & P & L & R & V & Y & S & I\end{array}$ CATCAGGGAGACTACATCCAACTTGGAGTGCCTCTGGAAAATAAGGAGAATGCGGAGTAT $\begin{array}{lllllllllllllllllllll}H & Q & G & D & Y & I & Q & L & G & V & P & L & E & N & K & E & N & A & E & Y\end{array}$ GAATATGAAGTTACTGAAGAAGACTGGGAGACAATATATCCTTGTCTTTCCCCAAAGAAT

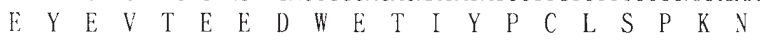
GACCAAATGATAGAAAAAAATAAGGAATTGAGAACTAMAAGGMMTTCAGTTTGGATGAA

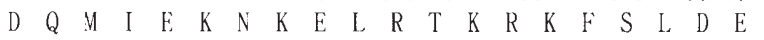
TTAGCAGGTCCTGGAGCTGAAGGCCCCTCAAATTTGAAATCCAAAATAAATAAAGTGTCT $\begin{array}{lllllllllllllllllllll}L & A & G & P & G & A & E & G & P & S & N & L & K & S & K & I & N & K & V & S\end{array}$ TGTGAATCTGGTCAGCCAGTGAAATCACAGGGGAAAGGTGAAGTGGCCAGTACACCCTCT $\begin{array}{llllllllllllllllllll}C & E & S & G & Q & P & V & K & S & Q & G & K & G & E & V & A & S & T & P & S\end{array}$ GACANTTTGGATCCTAAGTTGACTGCCCTTGAGCCAAGTAAGACCACAGGGGCTCCCATT $\begin{array}{llllllllllllllllllll}\text { D } & N & L & D & P & K & L & T & A & L & E & P & S & K & T & T & G & A & P & I\end{array}$ TACCCTGGCTTCCCCAAAGTCACAGAGGTTCATCATGAGCAGAAAGCCTCAAACTCTTCA $\begin{array}{llllllllllllllllllll}Y & P & G & F & P & K & V & T & E & V & H & H & E & Q & K & A & S & N & S & S\end{array}$ GCATCTCAGAGAGGTTACAGATGITTIAAGGTGACCATGTCCAGGATTCTGAGGCTCAAA

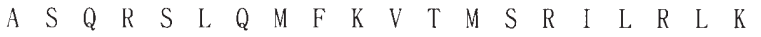
ATACAGATGCAGGAAAAACATGAAGCCGTTATGAATGTGAAAAAGCAGACCCAAAAGGGG $\begin{array}{llllllllllllllllllll}I & Q & M & Q & F & K & H & E & A & V & M & N & V & K & K & Q & T & Q & K & G\end{array}$ ACTCAAAGAAAGTTGTGCAAATGGAGCAGGAACTTCAGGACTTACAGTCCCAGCTGTGT

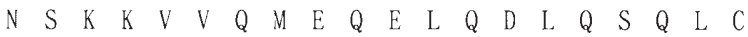
GCAGAGCAGGCTCAGCAGCAGGCAAGAGTGGAGCAACTAGAGAAGACTTTCCAGGAAGAG $\begin{array}{llllllllllllllllllll}A & E & Q & A & Q & Q & Q & A & R & V & E & Q & L & E & K & T & F & Q & E & E\end{array}$ GAACAGCATCTTCAGGGTTTGGAGATAGCCCAAGGAGAMAGGACCTGAAGCAACAGCTG

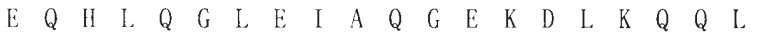
GCCCAGGCTCTGCAGGAGCATTGGGCTCTAATGGAAGAGCTAAATCGCAGCAAGAAGGAC A Q A A L. Q TTTGAMGCAATCATTCAAGCCAAGAACAMGAATTAGAGCAGACCAAGGAAGAGAAGGAG 1140 F $\quad E \begin{array}{lllllllllllllllllll} & A & I & I & Q & A & K & N & K & E & L & E & Q & T & K & E & E & K & E\end{array}$ AAGATGCAAGCACAGAAGGAAGAAGTTCTTAGCCACATGAATGATGTGCTAGAGAATGAG 1200 $\begin{array}{llllllllllllllllllll}K & M & Q & A & Q & K & E & E & V & L & S & H & M & N & D & V & L & E & N & E\end{array}$ CTCCAATGTATTAIYITGTTCAGAATACTTCATTGAGGCTGTCACCTTGAACTGTGCCCAC

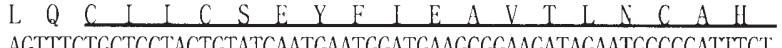
AGTTTCTGCTCCTACTGTATCAATGAATGGATGAAGCGGAAGATAGAATGCCCCATITGT 1320

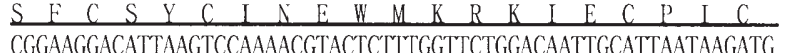
$\begin{array}{lllllllllllllllllllll}R & K & D & I & K & S & K & T & Y & S & L & V & L & D & \text { V } & C & \text { I } & N & K & M\end{array}$ GTAAATAATCTGAGCTCAGAAGTGAAAGAACGACGAATTGTTCTCATTAGGGAACGAMA 1440 $\begin{array}{lllllllllllllllllllll}V & N & N & L & S & S & E & V & K & E & R & R & I & V & L & I & R & E & R & K\end{array}$ GCAAAGAGATTGTTCTGAagaccgt getct aagggcat t tgaaagactgecaggt ag tgc A $\mathrm{K} \quad \mathrm{R}$ L $\mathrm{F}$ *

gagcetgagatggtctggaggat tctctctagcegtgactccgctgctctgaaggtcaac 1560 tgagaagtet tgt gggacagagact tgagt taggaagccetcagtcact tgect tccacg 1620 gtggecagcectget gccatcat tggctgaagcaccaccaggat tcacggcacceaactg $\quad \mathbf{1 6 8 0}$ ct tcagggtact tegtagactetgectcactacatgtcgaaagagt tatt tgagttctct $\quad 1740$ tctgttttttt taat tgt tgt tgt tgt tactgtt tgatacctcggaaacacctccgt 1800 tgacagt tget t tggataggt tggg tg tacccea tggct gectctgaaggcagtgtctat 1860 tt tgagaggat gget tace tet tet tgtgaaaatactatetcat t tectggaaataaa 1919

Fig. 1 Nucleotide sequence and deduced amino acid sequence of the human RING fnger cDNA. Asterisk denotes the termination codon. The RING finger motif is underlined. The nucleotide sequence reported here will appear in DDBJ, EMBL, and GenBank nucleotide sequence databases under accession number AB012770

coupled polymerase chain reaction (RT-PCR). Primers used for RT-PCR were to amplify the $1.7-\mathrm{kb}$ cDNA of the transcript. Considering its ubiquitous expression in a wide variety of human tissues, this gene could play an essential role in common cellular processes. It is notable that the gene was poorly expressed in spleen (Fig. 2).

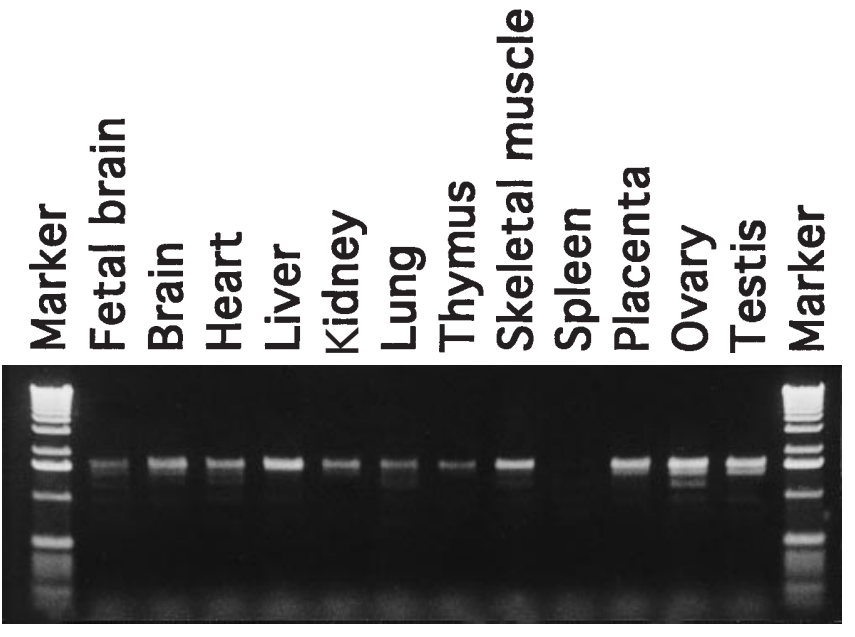

Fig. 2 Primers used for reverse transcription (RT)-polymerase chain reaction (PCR) were to amplify the $1.7-\mathrm{kb} \mathrm{cDNA}$ of the transcript. RT-PCR amplification primers were (5'-GGACAATTATGGACAACAAGAG') and (5'-CAAAGAAGAGGTAAGCCATCC-3'). The templates of the human tissues of $\operatorname{poly}(\mathrm{A})^{+}$RNAs were purchased from Clontech (Palo Alto, CA, USA). The cDNA templates for RTPCR were synthesized from $2 \mu \mathrm{g}$ of poly $(\mathrm{A})^{+}$, using excess amounts of Superscript II reverse transcriptase (GIBCO BRL, Gaithersburg, MD, USA) and random hexamer primers. PCR was carried out in a final volume of $10 \mu \mathrm{l}$ containing $1 \times$ LA-PCR buffer (Takara, Kyoto, Japan), $2 \mu \mathrm{M}$ each primer, $200 \mu \mathrm{M}$ each dNTP, $50 \mathrm{ng}$ template DNA, and 0.01 units of LA-Taq DNA polymerase (Takara). Temperature and time schedules were: 30 cycles at $95^{\circ} \mathrm{C}$ for $20 \mathrm{~s}$ and $62^{\circ} \mathrm{C}$ for $1 \mathrm{~min}$. PCR products were separated on $1 \%$ agarose gel with a 1 -kb ladder DNA marker (GIBCO BRL)

\section{Chromosomal assignment of the gene}

Chromosomal assignment of the gene was done by PCR analysis of a human/rodent somatic cell hybrid panel and a radiation hybrid panel, as described previously (Saito et al. 1995, 1997, Seki et al. 1997). Primers used for PCR amplification correspond to the $3^{\prime}$-untranslated region (UTR) of the gene (5'-CAAAGAAGAGGTAAGCCATCC-3') and (5'-GTTACTGTTTTGATACCTCGG-3') (121-bp PCR product). The specific amplified PCR product for human was detected only from the hybrid cell containing human chromosome 6 (data not shown). We performed further mapping analysis, using a PCR-based radiation hybrid panel (Genebridge 4; Research Genetics, 口) with the same primers as those used in the assay for the human/rodent somatic cell hybrid panel. Statistical analysis of the radiation hybrid data was performed using the RHMAPPER software package (http://wwwgenome.wi.mit.edu/cgi-bin/contig/rhmapper.pl). The data vector for the gene was 100000010000100001001100010000 $\begin{array}{lll}1111010100 & 0110010010 \quad 1011010001 & 0110100010\end{array}$ 00111001100121000000001 and the consequent report indicated that the gene was mapped between markers WI-4186 and WI-7940, both of which have been cytogenetically mapped to $6 \mathrm{p} 21.3$. The position of the gene is $6.29 \mathrm{cR}$ proximal to WI-4186. 


\section{Discussion}

The RING finger domain was first identified in the human RING1 protein, the gene of which was mapped on chromosome 6p21.3 (Freemont et al. 1991). Recently, two other RING finger protein genes were mapped on the $6 \mathrm{p} 21.3$ region (Kyushiki et al. 1997; Henry et al. 1997), and in the present study the fourth RING finger protein gene on chromosome 6 p21.3 is described. The RING finger protein gene family may exist as a cluster in this region. Some members of the RING finger family have been implicated in carcinogenesis and cell transformation. For example, $P M L$, rpf, and TIF1 have transforming capabilities when associated with chromosomal translocations (Takahashi et al. 1988, Goddard et al. 1991; Miki et al. 1991; LeDouarin et al. 1995). The major histocompatibility complex (MHC) exists in the human chromosome 6 p21.3 region, and a relatively high gene density has been observed. Since a large number of disorders are associated with the $\mathrm{MHC}$ region (Moller 1983; Trent and Ziegler 1992), our precise chromosomal positioning data for the novel zinc finger protein gene could contribute toward ongoing positional candidate approaches for the above-mentioned disease genes linked to this genomic locus.

\section{References}

Freemont PS, Hanson IM, Trowsdale J (1991) A novel cysteine-rich sequence motif. Cell 64: 483-484

Goddard AD, Borrow J, Freemont PS, Solomon E (1991) Characterization of a zinc finger gene disrupted by the $t(15 ; 17)$ in acute promyelocytic leukemia. Science 254: 1371-1374

Henry J, Ribouchon M, Depetris D, Mattei M, Offer C, Tazi-Ahnini R, Pontarotti P (1997) Cloning, structural analysis, and mapping of the $\mathrm{B} 30$ and B7 multigenic families to the major histocompatibility complex (MHC) and other chromosomal regions. Immunogenetics 46: 383-395
Kyushiki H, Kuga Y, Suzuki M, Takahashi E, Horie M (1997) Cloning, expression and mapping of a novel RING-finger gene (RNF5), a human homologue of a putative zinc-finger gene from Caenorhabditis elegans. Cytogenet Cell Genet 79: 114-117

LeDouarin B, Zechel C, Garnier JM, Lutz Y, Tora L, Pierrat P, Heery D, Gronemeyer H, Chambon P, Losson R (1995) The N-terminal part of TIF1, a putative mediator of the ligand-dependent activation function (AF-2) of nuclear receptors, is fused to B-raf in the oncogenic protein T18. EMBO J 14: 2020-2033

Mackay JP, Crossley M (1998) Zinc finger interactions. TIBS 23: 1-4

Maruyama K, Sugano S (1994) Oligo-capping: a simple method to replace the cap structure of eukaryotic mRNAs with oligoribonucleotides. Gene 138: 171-174

Miki T, Fleming TP, Crescenzi M, Molloy CJ, Blam SB, Reynolds SH, Aaronson SA (1991) Development of a highly efficient expression cDNA cloning system: application to oncogene isolation. Proc Natl Acad Sci USA 88: 5167-5171

Moller G (1983) HLA and disease susceptibility. Immunol Rev 70: $1-218$

Ohara O, Nagase T, Ishikawa K, Nakajima D, Ohhira M, Seki N, Nomura N (1997) Construction and characterization of human brain cDNA libraries suitable for analysis of cDNA clones encoding relatively large proteins. DNA Res 4: 53-59

Saito T, Seki N, Matsuda Y, Kitahara M, Murata M, Kanda N, Nomura N, Yamamoto T, Hori T (1995) Identification of the human ERK gene as a putative receptor tyrosine kinase and its chromosomal localization to 1p36.1: A comparative mapping of human, mouse, and rat chromosomes. Genomics 26: 382-384

Saito T, Seki N, Ishii H, Ohhira M, Hayashi A, Kozuma S, Hori T (1997) Complementary DNA cloning and chromosomal mapping of a novel phosphatidylinositol kinase gene. DNA Res 4: 301-305

Saurin AJ, Borden KL, Boddy MN, Freemont PS (1996) Does this have a familiar RING? Trends Biochem Sci 1 21: 208-214

Schwabe JW, Klug A (1994) Zinc mining for protein domains. Nat Struct Biol 1: 345-349

Seki N, Nimura Y, Ohhira M, Saito T, Ichimiya S, Nomura N, Nakagawara A (1997) Identification and chromosome assignment of a human gene encoding a novel phosphatidylinositol-3 kinase. DNA Res 4: 355-358

Suzuki Y, Yoshitomo-Nakagawa K, Maruyama K, Suyama A, Sugano S (1997) Construction and characterization of a full length-enriched and 5'-end-enriched cDNA library. Gene 200: 149-156

Takahashi M, Inaguma Y, Hiai H, Hirose F (1988) Developmentally regulated expression of a human "finger"-containing gene encoded by the $5^{\prime}$ half of the ret transforming gene. Mol Cell Biol 8: 18531856

Trent JM, Ziegler A (1993) Report of the first international workshop on human chromosome 6 mapping. Cytogenet Cell Genet 62: 65-87 